\title{
Requerimientos jurídicos de la administración de la educación a la luz de las exigencias de la administración educativa moderna
}

\author{
Legal Requirements of School Administrators Inlight of Modern Administrative Demands in Education
}

Recibido 22 setiembre 2014 • Aceptado 08 octubre 2014 • Corregido 30 noviembre 2014

\author{
Dennisse Carvajal Delgado \\ Liceo Franco Costarricense \\ San José, Costa Rica \\ dcarvajaldelgado@yahoo.com
}

\begin{abstract}
Resumen. El presente trabajo de investigación aplicada tuvo como objetivos generales el analizar los requerimientos jurídicos de la administración de la educación a la luz de las exigencias de la administración educativa moderna y la elaboración de una propuesta que oriente al profesional en administración de la educación en el abordaje de situaciones jurídicas desde el ejercicio de su puesto. Los objetivos específicos del presente estudio permitieron determinar aspectos fundamentales de la gestión jurídica de la educación que llevan a cabo los directores y las directoras del circuito 04 de la Dirección Regional de Educación San José Central (DRESJC). El tipo de investigación desarrollada es cualitativa de tipo fenomenológica. Se utiliza la entrevista abierta como instrumento para la recolección de datos para el estudio, visitando de manera personal once directores y directoras del circuito 04. Entre los hallazgos encontrados se determinan una serie de competencias y conocimientos necesarios para un adecuado ejercicio de la gestión jurídica de la educación, se identifica la normativa jurídica que todo director debe conocer, se identifican los conocimientos que tiene el personal directivo sobre el procedimiento administrativo y se evidencian una serie de limitaciones que actualmente poseen las y los profesionales en administración de la educación.
\end{abstract}

Palabras claves. Sociedad, educación, administración de la educación, administración educativa moderna, personal directivo, gestión jurídica de la educación, conocimientos, competencias gerenciales.

Abstract. This article is the conclusion of a research project analyzing the legal requirements pertaining to Costa Rica's educational administrative system in light of modern demands and guidelines for educational administrators in addressing legal demands. This will serve as a legal framework guideline for school directors from the 4th circuit of the Metropolitan Regional Education Office in San Jose (DRESJC). This research project is qualitative as well as phenomenological and based on open interviews to collect study data based on visits made to eleven school directors/ principals in the 4th Circuit. The findings conclude that specific skills and knowledge is required for adequately understanding the legal framework of the Costa Rican educational system and putting into practice. It also identifies those laws and regulations that all school directors/principals should

1 Máster en Gestión Jurídica de la Educación y Licenciada en Administración Educativa de la Universidad de Costa Rica. Licenciada y Bachiller en Pedagogía de la Universidad Nacional. Actualmente labora como asistente administrativa y pedagógica del Liceo Franco Costarricense, con amplia experiencia en docencia en centros educativos públicos del Ministerio de Educación Pública y de instituciones educativas privadas. 
know and compared it to their current understanding with regards to how these laws are applied to their administrative duties and existing knowledge gaps among school administrators.

Key Words. Educational administration, school directors, administrative staff, legal management of educational, administrative competencies.

\section{Introducción}

A través de los años, la educación ha representado, de manera ineludible, la llave fundamental para el desarrollo personal, profesional y laboral del individuo y, por ende, de la sociedad. A partir de esta, se propone la adquisición constante de nuevos aprendizajes y la reconstrucción continua de los saberes ya aprendidos para la adaptación eficaz en la llamada "sociedad de la información y el conocimiento", en la que se desenvuelve el ser humano en la actualidad.

Por tal motivo, la educación en este sentido conlleva una responsabilidad sobre sus hombros, que le exige crear cambios oportunos, significativos y que se ajusten a la realidad y a las diferentes exigencias del país y de las personas que lo conforman.

Las instituciones educativas y sus protagonistas deben convertirse en agentes de cambio que trabajen en conjunto con la sociedad, en el logro de objetivos colectivos y en respuesta a las necesidades que se presenten. Tal y como lo plantean Garbanzo y Orozco (2010), la sociedad del conocimiento y la información necesita sistemas educativos con capacidad para aprender y desarrollar nuevas competencias y, en este sentido, las organizaciones educativas se convierten en piezas fundamentales para lograr en gran medida los desafíos que se plantean en la actualidad.

En la sociedad costarricense, la educación representa uno de los pilares básicos para el progreso de la colectividad, cimentando el sistema educativo en diferentes ideales que se establecen de modo general para todos y todas al logro de una sociedad más integral y equitativa.

El sistema educativo permite, pormedio delos procesos deinteracción pedagógica ylos diferentes actores de la comunidad educativa, la construcción e integración de los ideales costarricenses que señalan las diferentes políticas y planes educativos, los cuales se construyen a partir de las diferentes necesidades que presenta la sociedad y de las demandas de los individuos que la integran.

Por tal motivo, la administración del sistema educativo y de la educación en general, es de vital importancia en la gestión de procesos de calidad que respondan de manera significativa a las necesidades, intereses y particularidades de una sociedad que cada día exige un mayor conocimiento y utilización de las nuevas tecnologías de la información y la comunicación en cada una de las esferas de la vida humana.

La administración de la educación debe trabajar y desarrollarse en función de la realidad de un país, de su sociedad y de los ideales que se ha propuesto alcanzar, tal y como lo señalan 
Garbanzo y Orozco (2007), la administración de la educación se debe a una sociedad en particular, a un modelo de sociedad, a sus necesidades, sueños y desafíos, por tal motivo debe trabajar de manera articulada al proyecto social. Aquí radica la importancia y el papel fundamental del profesional en administración de la educación como gestor o gestora de cambio y de transformación educativa, política, social y cultural desde la comunidad educativa que lidera. Su función en el quehacer pedagógico y administrativo influye, en gran medida, en el progreso o estancamiento de una sociedad que necesita más y mejores reformas de cambio que se ajusten a su realidad y expectativa.

En la actualidad, las personas profesionales en administración de la educación se enfrentan a una sociedad que demanda retos y desafíos constantes; una sociedad que a través de los años, de manera notoria, ha perdido valores fundamentales como el respeto, la solidaridad, la tolerancia y la empatía, una sociedad que busca mejorar su calidad de vida valiéndose de un sistema educativo que le permita acceder a mejores oportunidades de progreso y que, a su vez, responda a las necesidades que enfrenta. Por tal motivo, la responsabilidad que recae sobre los administradores y administradoras de la educación es compleja y desafiante, y el individuo que la asume debe poseer una mínima preparación interdisciplinaria que le permita atender de manera eficiente y eficaz la organización educativa que lidera.

\section{Justificación del problema y su importancia}

En Costa Rica, la educación representa un pilar esencial para la construcción del tipo de ciudadano ideal, por lo que el Estado se ha encargado de plasmar, en su marco legal, la relevancia que tiene la educación para la sociedad; así como los derechos y las obligaciones inherentes que tiene cada costarricense y gobernante de este país para el logro de los objetivos sociales.

En este sentido, el papel de la administración de la educación resulta clave para garantizar, a la comunidad estudiantil, una formación de calidad; es decir, un tipo de educación que responda de manera significativa a las necesidades, intereses y particularidades de esos actores que, día a día, requieren mejorar su condición de vida, de familia y sociedad.

Por tal razón, la administración de la educación se destaca como la disciplina por excelencia que se encarga de prever, organizar, dirigir, controlar y evaluar los diferentes procesos pedagógicos, curriculares, relacionales y administrativos que se llevan a cabo en una organización educativa. Las múltiples gestiones que debe realizar un directivo, le implica poseer una serie de conocimientos y destrezas que le permitan dirigir los diferentes procedimientos del centro educativo de la mejor manera.

En la actualidad, se hace necesario que las personas profesionales en administración de la educación posean conocimientos y competencias específicas en el ejercicio de la gestión 
jurídica que realizan desde sus centros educativos, en aras de atender de manera adecuada su labor, acorde con el principio de legalidad que establece el ordenamiento jurídico costarricense.

De acuerdo con lo anterior y en virtud de las diferentes situaciones que enfrentan en la cotidianidad, la gestión jurídica permite a los administradores y administradoras de la educación desenvolverse en la organización que lideran con mayores y mejores herramientas en la construcción de una organización más integral y acorde con las necesidades que se presentan.

Ante lo anteriormente señalado, se hace necesario analizar los requerimientos jurídicos de la administración de la educación a la luz de las exigencias de la administración educativa moderna como parte inherente de la gestión de las organizaciones educativas. Todo ello, con el propósito de profundizar en aquellos requerimientos jurídicos que tienen los administradores de la educación, de acuerdo con los conocimientos y competencias con los que deben contar, la normativa legal de uso común que deben utilizar en la gestión que realizan y los procedimientos de abordaje que realizan ante las situaciones jurídicas que enfrentan desde la cotidianidad de su función administrativa.

Para la elaboración del estudio se propone una serie de objetivos generales y específicos que responden a los elementos que se deben contemplar para realizar la presente investigación.

\section{Objetivos generales}

- Analizar los requerimientos jurídicos de la administración de la educación a la luz de las exigencias de la administración educativa moderna.

- Elaboración de una propuesta de capacitación para los administradores de la educación costarricense en temáticas jurídicas básicas para su gestión en las instituciones educativas.

\section{Objetivos específicos}

- Determinar los conocimientos y competencias que deben poseer los administradores de la educación costarricense en el marco jurídico de su gestión en la práctica de la administración educativa moderna.

- Identificar las normas jurídicas de uso común que utilizan los administradores de la educación costarricense en la práctica de la administración educativa moderna.

- Reconocer los procedimientos de abordaje de las situaciones jurídicas que realizan los administradores de la educación del circuito 04 de la Dirección Regional de Educación San José Central.

- Establecer eventuales limitaciones en el conocimiento jurídico que enfrentan los administradores de la educación del circuito 04 de la Dirección Regional de Educación San José Central. 
Esta investigación se realizó en el sistema educativo costarricense, en el año 2014, con el apoyo de once instituciones educativas públicas de primaria y secundaria del circuito 04 de la Dirección Regional de Educación San José Central (DRESJC) del Ministerio de Educación Pública (MEP).

\section{Marco referencial}

\section{Funciones del profesional en administración de la educación de acuerdo con el ordenamiento jurídico costarricense}

Las administradoras y los administradores de la educación de las diferentes instituciones educativas públicas costarricenses poseen una investidura como funcionarias y funcionarios públicos, por lo que son acreedores de las responsabilidades y funciones señaladas en la Ley General de Administración Pública (LGAP). Tal y como se señala en el Artículo 111 de la LGADP (1978), la persona que presta servicios a la administración o a nombre y por cuenta de esta, se considera servidor público.

Los profesionales en administración de la educación ejercen una relación jerárquica sobre la comunidad educativa con la que labora, de acuerdo con el Artículo 101 de la LGAP (1978): “Habrá relación jerárquica entre superior e inferior cuando ambos desempeñen funciones de la misma naturaleza". Por tal motivo, el director o directora de un centro educativo tendrá, de acuerdo con el artículo 102 de esta Ley, una serie de potestades.

Los directores y directoras realizan una labor fundamental en la gestión de las organizaciones educativas que abarca tareas de planificación, seguimiento, control, supervisión de los diferentes actores y procesos inherentes a todo sistema educativo.

De acuerdo con el Manual Descriptivo de Puestos Docentes y Administrativo-Docentes del Servicio Civil (2014), las funciones del administrador de la educación, independientemente del tipo de dirección o nivel educativo que tenga a cargo, son las puntuales y requieren gran responsabilidad por parte del personal directivo.

Específicamente, en el Reglamento General de Establecimientos Oficiales de Enseñanza de la Educación Media (MEP, 1982), en su artículo 6, se establece que cada colegio estará a cargo de un Director, el cual será el responsable directo de la administración del plantel.

Asimismo, en el artículo 7 de este mismo Reglamento (MEP, 1982), se señalan de manera específica las funciones del administrador de la educación.

\section{Conceptos jurídicos básicos en la gestión jurídica de la educación}

Las directoras y los directores de organizaciones educativas, además de cumplir a cabalidad con las funciones que establecen las leyes y los reglamentos anteriores, deben poseer 
un conocimiento general de la Constitución Política, así como de leyes, reglamentos, decretos, manuales y demás documentos de carácter legal y administrativo que establece el ordenamiento jurídico costarricense y en el ejercicio de su función como administradores de la educación.

Algunos de los conceptos claves que debe manejar el administrador de la educación, de acuerdo con lo indicado por Benavides, Chavarría y González (1992), son los siguientes: norma jurídica, ley, decreto, reglamento, manual, actos administrativos, acuerdos y resoluciones.

\section{Procedimiento Administrativo, debido proceso y principio de legalidad}

Dentro del abordaje de situaciones jurídicas que enfrenta el profesional en administración de la educación, en la cotidianidad de la organización, debe aplicar las normativas que establece el ordenamiento jurídico para gestionar los procedimientos establecidos de acuerdo con los principios constitucionales del debido proceso y del principio de legalidad.

Los directores y directoras de los centros educativos deben cumplir y respetar los procedimientos establecidos por la legislación costarricense para gestionar las situaciones legales de diferente índole que se presentan en su realidad inmediata.

Los artículos 214, 215 y 216 de la Ley General de Administración Pública (1978) establecen las características generales del procedimiento administrativo.

Con respecto al debido proceso, el artículo 173, inciso 3) de la Ley General de Administración Pública (1978) señala: "Antes de anular los actos referidos en este artículo, el acto final debe estar precedido por un procedimiento administrativo ordinario, en el que se hayan observado los principios y las garantías del debido proceso y se haya brindado audiencia a todas las partes involucradas".

Asimismo, el artículo 11, inciso 1) de la Ley General de la Administración Pública (1978) establece: "La Administración Pública actuará sometida al ordenamiento jurídico y solo podrá realizar aquellos actos o prestar aquellos servicios públicos que autorice dicho ordenamiento, según la escala jerárquica de sus fuentes".

\section{Jerarquía de las normas jurídicas}

Conocer el orden de ámbito y de la aplicación de cada norma jurídica le permite al directivo de las instituciones educativas comprender la relevancia de cada norma y utilizarla adecuadamente, de acuerdo con su marco de acción y legitimidad.

De acuerdo con la Ley General de la Administración Pública (1978), las fuentes de ordenamiento jurídico, en su orden jerárquico son las siguientes:

- La Constitución Política y leyes con valor constitucional 
- Los Tratados o Convenios Internacionales

- Las leyes y demás actos con valor de ley

- Los Decretos

- Los Reglamentos

- Los contratos colectivos

- La costumbre

Por tal motivo, de acuerdo con lo expuesto anteriormente, se hace necesario que cada director y directora de las organizaciones educativas tengan conocimiento de una serie de normas jurídicas que atañen su labor como administradores de la institución educativa que lideran, tales como:

- Constitución Política de Costa Rica

- Declaración Americana de los Derechos y Deberes del Hombre

- Pacto Internacional de Derechos Económicos, Sociales y Culturales

- Convención Americana sobre derechos humanos

- Protocolo Adicional a la Convención Americana sobre Derechos Humanos en Materia de Derechos Económicos, Sociales y Culturales

- Convención sobre los Derechos del Niño

- Estatuto del Servicio Civil:Título l y Título II

- Ley Fundamental de Educación

- Ley General de la Administración Pública

- Ley de Contratación Administrativa

- Ley contra el Enriquecimiento llícito en el ejercicio de la Función Pública

- Ley de Carrera Docente y su reglamento

- Ley 7600 y su reglamento

- Código de Educación

- Código de la Niñez y la Adolescencia

- Reglamento Interno de Trabajo del MEP

- Reglamentos de Conserjería y Vigilancia

- Reglamento de Juntas y Patronatos

- Reglamento de Matrícula y Traslados

- Reglamento de Evaluación de los Aprendizajes

- Manual Descriptivo de Puestos Docentes del Servicio Civil. 


\section{Referente teórico}

\section{Educación y sociedad}

Educar, desde los tiempos más primitivos y hasta la actualidad, ha representado el medio por excelencia que ha permitido a familia, escuela y sociedad la transmisión y construcción de saberes y conocimientos como parte de su herencia cultural y al logro del desarrollo integral de cada individuo, por lo que la educación resulta intrínseca a todo ser humano.

La educación, por lo tanto, es una herramienta para el ser humano que le permitirá acceder a una mejor y mayor calidad de vida y que tendrá como objeto la satisfacción de este. Al respecto, Ruiz (2006) señala:

Educación y calidad de vida están íntimamente asociadas (...) en primer lugar, la educación constituye el principal instrumento para el progreso individual y, en segundo término, cristaliza a la vez las posibilidades de una colectividad para dotarse de mejores condiciones en su calidad de vida. (p. 19)

El concepto "calidad de vida" trabaja de manera paralela con la educación, la cual desempeña un papel protagónico para la construcción de un futuro esperanzador para el individuo, en una sociedad compleja y dinámica.

La actual sociedad ha tomado la educación como base fundamental para coadyuvar en el progreso o el rezago del individuo y su inserción o no a un mundo competitivo que demanda nuevas y mejores experiencias de aprendizaje.

A partir de la educación, se propone la adquisición constante de nuevos aprendizajes que respondan, de manera significativa, a una era del conocimiento e información que presenta una realidad turbulenta y que se encuentra llena de elementos que la hacen sumamente compleja, exigiéndole al individuo un mayor y mejor conocimiento.

\section{Administración de la educación}

En el apartado anterior, se detalló el papel relevante que tiene la educación como agente transformador y de progreso para una sociedad que, en la actualidad, presenta una serie de retos y desafíos para integrarse de manera eficaz a un mundo globalizado y a una era cargada de acelerados cambios tecnológicos, de comunicación e información.

De aquí radica la importancia de administrar la educación de manera estratégica y acertada, de modo que responda a las necesidades del presente siglo y se ajuste a los intereses y particularidades de los individuos que conforman la sociedad. Tal y como lo señalan Garbanzo y $\operatorname{Orozco}(2007$, p. 95), “la administración de la educación se enriquece a sí misma en la medida 
en que trabaje articulada al proyecto social", ya que no se debe a sí misma sino a una sociedad específica que presenta desafíos y retos constantes en el ejercicio de su labor.

La administración de la educación como disciplina, debe responder a las diferentes necesidades que plantea la actual sociedad y formular mecanismos que le permitan liderar comunidades educativas que aprendan y se desenvuelvan en situaciones reales, dinámicas y complejas.

En el presente siglo, la administración de la educación representa uno de los medios que la sociedad utiliza para llevar a cabo planes y políticas nacionales de acuerdo con los marcos internacionales existentes, los cuales promueven la integración mundial y el avance social, político, cultural, económico y ambiental de los pueblos y comunidades de una nación; solo una administración de la educación sabia, estratégica y eficaz permitirá implementar reformas que atiendan a las solicitudes de la presente era.

\section{Administración educativa moderna}

La actual sociedad del conocimiento y la información en la que se desenvuelven las organizaciones educativas, trae de manera implícita retos y desafíos para la administración de la educación y por ende, para el profesional encargado de liderar este proceso. Sobre esta línea, Garbanzo y Orozco (2010) señalan lo siguiente:

La sociedad del conocimiento, como se le denomina hoy, necesita sistemas educativos con capacidad para aprender y desarrollar nuevas competencias. En este campo, las organizaciones educativas se vuelven trascendentales, un adecuado liderazgo tras ellas, las posiciona en un contexto de alta competitividad. (p. 18)

La administración de centros educativos, en la actualidad, debe contar con gerentes que logren colocar a las organizaciones educativas en contextos visionarios que permitan integrar las políticas internacionales a las nacionales, que integren de manera natural las características del presente siglo y que responda, de manera significativa, a las necesidades, intereses y particularidades de sus miembros.

La sociedad demanda organizaciones educativas pertinentes con la realidad en que se vive, organizaciones que logren insertar al individuo en un mundo globalizado que exige un mejor y mayor conocimiento, así como el desarrollo de competencias que permitan su integración y progreso en todas las áreas.

Al respecto, Garbanzo y Orozco (2007) señalan lo siguiente:

Para enfrentar los diferentes desafíos que interpelan a la educación, se requiere de un nuevo paradigma de la administración de la educación, epistemológicamente renovada, de manera que el sistema educativo trabaje de acuerdo con parámetros de calidad, como condición para aspirar a lograr, con mayor pertinencia, los fines y objetivos de la educación. (p. 100) 
Un nuevo paradigma de la administración de la educación permite conducir las organizaciones educativas, de manera pertinente, hacia transformaciones profundas en contextos competitivos que formen individuos capacitados, con las destrezas necesarias para influir en la creación de más y mejores condiciones de vida.

\section{El profesional y la profesional en administración de la educación}

Los directores y directoras de los centros educativos, al asumir el reto y la responsabilidad de dirigir organizaciones educativas, asumen también la compleja tarea de conducir a su comunidad educativa a más y mejores oportunidades de progreso y desarrollo en medio de una sociedad exigente.

El profesional en administración de la educación, como gerente de una organización y en su rol como superior jerárquico de personal, estudiantes y padres de familia, debe llevar a cabo labores en diferentes temáticas, lo que implica que, de manera ineludible, posea una serie de competencias que le permitan enfrentar los retos que día a día se le presentan en su ambiente de trabajo. Tal y como indica Cons (2004, p. 1):"(...) los administradores educativos deben reunir las competencias necesarias para abordar los diferentes fenómenos que surgen tanto a lo interno como a lo externo de las organizaciones educativas".

En este sentido, las funciones de los administradores en las instituciones educativas no se limitan a las cuatro paredes del centro o a la población estudiantil con la que trabajan, su rol como líderes educativos les demanda además, responsabilidades y representación fuera del plantel en su calidad como directores, lo que implica la ejecución de funciones inherentes a su cargo.

Por consiguiente, el papel de los directores y directoras de las organizaciones educativas, en su rol como líderes del proceso pedagógico y de los actores de la comunidad educativa, cumplen con responsabilidades fundamentales al logro de las políticas educativas nacionales e internacionales. Sobre esta línea, García, Rojas y Campos (2002) afirman:

El director es la autoridad formal de la institución educativa. Se espera de él el ejercicio del liderazgo en las diversas labores que desempeña y responsable de la eficacia y del progreso de la institución (...) está encargado de dirigir una organización compuesta por diversos actores sociales: docentes, secretarias, conserjes, alumnos, padres de familia; su labor es compleja ya que administra recursos físicos y didácticos, personas y programas educativos. (p. 20)

La gestión que realizan los profesionales en administración de la educación requiere ser acertada e ir acorde con la realidad en la que se encuentra implícita la organización educativa y los miembros que la conforman.

La labor del profesional en administración de una organización educativa debe responder a las diferentes necesidades, intereses y particularidades de los actores directos o indirectos del proceso educativo, es decir, debe poseer un carácter profundamente estratégico orientado al logro de la misión, visión y objetivos organizacionales. 


\section{Gestión jurídica de la educación}

Dentro de los conocimientos, gestiones y competencias que debe desarrollar un directivo dentro de la organización educativa que lidera, hay una que en los últimos tiempos ha resultado fundamental en el ejercicio de su labor como administrador y administradora de la educación para enfrentar las situaciones de conflicto: la gestión jurídica.

Por lo anterior, el profesional en administración de la educación establece una serie de etapas desde su contexto, realidad y recursos para gestionar las situaciones jurídicas inherentes a toda organización educativa, las cuales deben ser dirigidas desde la estrategia o estrategias que establezca su líder.

La gestión jurídica de la educación que se lleva a cabo en las organizaciones educativas implica para el profesional en administración poseer un conocimiento estratégico y general de las leyes, normas, reglamentos, decretos y circulares del ordenamiento jurídico existente, de forma que le permitan respaldar y fundamentar sus acciones para el cumplimiento de deberes o en la resolución de conflictos académicos, administrativos, económicos o relacionales que son comunes en las instituciones educativas, esto es, el abordaje de las situaciones jurídicas.

Al respecto, Chacón (2012) define la gestión jurídica de la educación de la siguiente manera:

La gestión jurídica en materia educativa, implica una serie de actividades de control por parte del administrador de la educación. Según esto, una gestión jurídica eficaz exige que el mismo posea un conocimiento profundo en aspectos legales relacionados con su quehacer, sobre todo en temas referentes al derecho educativo, servicio público, la administración pública, los derechos y deberes de sus funcionarios, los deberes y derechos de estudiantes y padres de familia, cuestiones relativas a la ética, a legislación laboral, el debido proceso, el conocimiento de las leyes, normas y reglamentos relacionados con el área educativa, entre otras. (p. 64)

Tal y como lo plantea el autor, el profesional en administración de la educación debe encontrarse preparado para los diferentes retos que se presentan en la institución que dirige; retos que implican conocimiento en legislación educativa y competencias que le permitan desenvolverse con asertividad ante situaciones de conflicto.

Los directivos de centros educativos, en aras de cumplir con las políticas educativas, los deberes y derechos de la población estudiantil y con las normas que los órganos ministeriales establecen con respecto a los deberes que todo funcionario debe cumplir, se ve implicado en procesos y situaciones de conflicto que, en la mayoría de las ocasiones, desembocan en temáticas legales, las cuales debe resolver de acuerdo con el bloque de legalidad vigente.

De aquí radica la importancia de formar y capacitar al personal directivo en temáticas de índole legal que tienen relación directa o indirecta sobre la función como administradores 
y administradores de la educación, pues la formación que reciben en las universidades, en su mayoría, no responden a la realidad que enfrenta el personal directivo al dirigir una comunidad educativa desde la función pública.

\section{Referente Metodológico}

La presente investigación se enmarcó dentro de un paradigma cualitativo, cuyo centro de interés son los significados de las acciones humanas. El enfoque cualitativo según Barrantes (2007) busca llegar al conocimiento "desde dentro", por medio del entendimiento de intenciones y el uso de la empatía. Además, es de tipo fenomenológica, puesto que "lo que distingue a este diseño de otros diseños cualitativos es la o las experiencias del participante o participantes como centro de indagación" (Hernández, Fernández y Baptista, 2010, p. 712).

Para efectos de esta investigación, la población entrevistada la conforman once profesionales en administración de la educación del circuito 04 de la Dirección Regional de Educación de San José Central, de instituciones educativas públicas que brindan servicios educativos de prescolar, primaria o secundaria.

Seguidamente, se presenta la operacionalización de objetivos que fundamentan la investigación, la cual incluye objetivos, categorías de análisis, definiciones de las categorías desde lo conceptual y lo operativo, así como sus indicadores e instrumentalización.

\section{Tabla 1}

Operacionalización objetivo específico 1: Conocimientos y competencias de los administradores de la educación costarricense en el marco jurídico de su gestión en la práctica de la administración educativa moderna

OBJETIVO GENERAL: Análisis de los requerimientos jurídicos de la administración de la educación a la luz de las exigencias de la administración educativa moderna

Objetivo específico: Determinar los conocimientos y competencias que deben poseer los administradores de la educación costarricense en el marco jurídico de su gestión en la práctica de la administración educativa moderna.

Categoría de análisis: Conocimientos y competencias que deben poseer los administradores de la educación costarricense en el marco jurídico de su gestión en la práctica de la administración educativa moderna.

Definición conceptual: De acuerdo con Cruz y Pacheco (2003, p. 5): "el conocimiento debe entenderse como una construcción mental humana, cuyo fin es ampliar nuestro entendimiento de la realidad". Cruz y Pacheco (2003) definen conocimiento de la siguiente manera: "El conocimiento es un insumo imprescindible del sujeto para tomar decisiones que le permiten sobrevivir individual y colectivamente. Asimismo, no hay que olvidar que el hombre forma parte también de esa realidad que desea y quiere conocer y modificar, en este sentido, el hombre no solo transforma la realidad para sobrevivir, sino que en ese proceso de cambio se transforma él mismo física, psicológica y culturalmente. Así el hombre, con base en el conocimiento, transforma transformándose, y transformándose transforma la realidad". (p. 6) 
Rev. Gestión de la Educación, Vol. 5, N 1, [1-34], ISSN: 2215-2288, enero-junio, 2015

DOI: http://dx.doi.org/10.15517/rge.v5i1.17841

URL: http://revistas.ucr.ac.cr/index.php/gestedu

Barrantes (2007) indica que el conocimiento puede ser de dos géneros:

$1^{\circ}$ ) Conocimiento inmediato, basado en la experiencia de cada persona

$2^{\circ}$ ) Conocimiento mediato o intelectual, adquirido a partir de otros conocimientos que la persona ya posee. (p. 15)

Cons (2004, p. 1):“(...) los administradores educativos deben reunir las competencias necesarias para abordar los diferentes fenómenos que surgen tanto a lo interno como a lo externo de las organizaciones educativas".

Frade (2009) resume el significado del concepto de competencias, de la siguiente manera:

a) Son una capacidad cognitivo-conductual, es decir, se refieren a nuestra capacidad de pensar, conocer y sentir, que se traduce necesariamente en un desempeño.

b) Incluyen conocimientos, capacidades, aptitudes, habilidades, destrezas, creencias, intuiciones, sensibilidad, motivación y ganas de hacer las cosas, así como la evaluación del propio desempeño (...)

c) Son una respuesta adaptativa a las demandas del entorno (...)

En el área de la administración de la educación, se podrían enumerar seis competencias fundamentales que propone Frade (2009) para el ejercicio del cargo:

1. Competencias Jurídicas: quien se hace responsable de resolver los problemas sobre la jurisdicción de algo, o bien del ámbito de la competencia de alguien, o quien cuenta con esa capacidad.

2. Competencias adaptativas: se refieren a la capacidad para interactuar efectivamente en el ambiente y se caracterizan por la adquisición de experiencia, el uso del conocimiento, creencias, valores, actitudes y esquemas de interpretación de lo que se vive, es decir, por cómo se interpreta el mundo. Dentro de estas se incluyen todas las habilidades de evaluación propia, de lo que se es, se quiere hacer y se hizo.

3. Competencias de acción: son aquellas que además de acentuar las competencias cognitivas incluyen la acción necesaria para lograr el éxito de la tarea, e incluyen resolución de problemas, habilidades de pensamiento, dominio de cierto conocimiento, confianza para hacerlo y capacidades para relacionarse con los demás.

4. Competencias laborales: capacidad de ser efectivo, capaz, apto idóneo para llevar a cabo la tarea que se requiere para un puesto específico.

5. Competencias para la vida: es el conjunto de conocimientos, habilidades, destrezas, actitudes, valores, creencias y principios que se ponen en juego para resolver los problemas y situaciones que emergen en un momento histórico determinado que le toca vivir al sujeto que interactúa con el ambiente.

6. Competencias clave: conjunto de conocimientos, habilidades, destrezas, actitudes y valores que se requieren para salir adelante, para ser ciudadano responsable, sujeto de derechos y obligaciones. Son vitales para seguir aprendiendo a lo largo de la vida, pues son la base del aprender a aprender. (pp. 80-82)

Hellriegel y Slocum (2002, p. 5) indica que las competencias gerenciales"son conjuntos de conocimientos, destrezas, comportamientos y actitudes que necesita una persona para ser eficiente en una amplia gama de labores gerenciales y en diversas organizaciones".

Hellriegel y Slocum (2002) señala las principales competencias gerenciales, así como sus características generales:

Manejo de personal

Integridad y comportamiento ético

Dinamismo y capacidad de resistencia

Equilibrio de las exigencias laborales y personales

Conciencia y desarrollo personal 


\author{
Comunicación \\ Comunicación Informal \\ Comunicación Formal \\ Negociación \\ Planeación y administración \\ Recopilar información, analizarla y resolver problemas \\ Planear y organizar proyectos \\ Administrar tiempo \\ Presupuestar y administrar finanzas \\ Trabajo en equipo \\ Formación de equipos \\ Creación de un ambiente de apoyo \\ Manejo de las dinámicas de un equipo \\ Acción estratégica \\ Entender el sector educativo \\ Comprender la organización \\ Adoptar acciones estratégicas \\ Globalización \\ Conocimiento y comprensión de la cultura \\ Apertura y sensibilidad cultural.
}

Según Arroyo (2011), las competencias o capacidades humanas del director strategos, son un conjunto complejo de conocimientos, habilidades, actitudes y valores que el director pone en juego cuando actúa en el ejercicio propio de su profesión, para llevar a cabo tareas diversas y responder a demandas complejas de la forma deseada o esperada, dentro de una determinada realidad.(p. 75)

Chacón (2012) define la gestión jurídica de la educación de la siguiente manera: La gestión jurídica en materia educativa, implica una serie de actividades de control por parte del administrador de la educación. Según esto, una gestión jurídica eficaz exige que el mismo posea un conocimiento profundo en aspectos legales relacionados con su quehacer, sobre todo en temas referentes al derecho educativo, servicio público, la administración pública, los derechos y deberes de sus funcionarios, los deberes y derechos de estudiantes y padres de familia, cuestiones relativas a la ética, a legislación laboral, el debido proceso, el conocimiento de las leyes, normas y reglamentos relacionados con el área educativa, entre otras. (p. 64)

Según Garbanzo y Orozco (2007), para enfrentar los diferentes desafíos que interpelan a la educación, se requiere de un nuevo paradigma de la administración de la educación, epistemológicamente renovada, de manera que el sistema educativo trabaje de acuerdo con parámetros de calidad, como condición para aspirar a lograr, con mayor pertinencia, los fines y objetivos de la educación. (p.100)

Definición operacional: Los conocimientos y competencias del personal directivo son aquellos saberes cognitivos en el campo jurídico de la educación y su administración, así como las habilidades interpersonales, comunicativas y físicas que requieren los administradores de la educación del circuito 04 de la Dirección Regional de Educación San José Central en el ejercicio de su puesto como líderes de organizaciones que se encuentran inmersas en una sociedad que cada día le exige mayores retos y desafíos dentro de la gestión jurídica que deben llevar a cabo para responder de manera significativa a los diferentes escenarios que se presentan cotidianamente en las organizaciones educativas.

A nivel cognitivo el profesional en administración de la educación debe poseer un amplio manejo del ordenamiento jurídico que atañe su quehacer como gerente del centro educativo. Dentro de las habilidades y conocimientos que deben poseer se encuentran:

\title{
CONOCIMIENTOS EN EL CAMPO JURÍDICO \\ COMPETENCIAS EN EL CAMPO JURÍDICO \\ Saberes generales en: \\ Habilidades:
}

Derecho como ciencia. Ramas del Derecho: Derecho Público, Administrativas:llevaracabolas diferentesfunciones delaAdministración: Derecho Administrativo, Derecho Constitucional, Derecho planear, coordinar, dirigir, supervisar y controlar con esmero, eficiencia y Educativo eficacia en el ejercicio de su puesto como administrador de la educación 

La importancia de la gestión jurídica en el ejercicio de la función de la
administración de la educación
Interpersonales: poseer inteligencia emocional para relacionarse con empatía, humildad, firmeza y respeto a los miembros de la comunidad educativa o a entes que forman parte del sistema educativo

Fuentes del Derecho escritas (convenios, leyes, decretos, reglamentos) y no escritas (costumbre, jurisprudencia)

Jerarquía de las normas jurídicas para su utilización

Intrapersonales: Reflejar una sana autoestima, autocontrol, auto criticidad, proactividad, ética profesional, humildad, prudencia y alta capacidad de escucha

Comunicativas: comunicarse de manera asertiva y estratégica con los miembros de la comunidad educativa o a entes que forman parte del sistema educativo

Legislación Costarricense: Constitución Política de Costa Rica, Ley General de Administración Pública, Ley de Contratación Administrativa, Ley contra el Enriquecimiento llícito en el ejercicio de la Función Pública, Ley 7600

Jurídicas: abordar las situaciones jurídicas de manera eficiente y eficaz, con proactividad, poniendo en práctica la amplia gama de conocimientos sobre el ordenamiento jurídico costarricense y experiencia laboral que posee en legislación educativa

Legislación Educativa: Artículos referentes a la educación como derecho, su importancia, y administración, consagrados en las normas supremas del ordenamiento jurídico tales como Constitución Política de Costa Rica, los Convenios Internacionales y la Jurisprudencia de la Sala Constitucional. Asimismo, saberes generales sobre Leyes, Reglamentos, Decretos y demás documentos que aborden el sistema educativo.

Procedimientos para llevar a cabo el debido proceso en cualquier acto administrativo que realice como funcionario público
Orales: poseer un excelente uso de la palabra, dirigirse de manera sabia, prudente, humilde y firme a la comunidad educativa o a otros entes involucrados en el proceso por abordar

Escritas: poseer habilidades en redacción y ortografía para elaborar documentación de calidad y pertinencia, en el ejercicio de su función como administrador de la educación

Liderazgo y Trabajo en Equipo: capacidad para liderar un equipo de trabajo, propiciando su participación y gestionando de manera estratégica su talento en la resolución de situaciones que se presentan en la cotidianidad de las organizaciones educativas

Negociación: capacidad para dirigir el conflicto, convertirse en mediador en diferentes situaciones o buscar un abanico de soluciones para las diferentes situaciones que se presentan en la organización educativa que lidera

Indicadores:

- Conocimientos y competencias en administración que debe poseer el director para llevar a cabo una gestión jurídica adecuada en las organizaciones educativas.

- Conocimientos en administración como: Administración general, principios y procesos, administración de la educación, administración educativa moderna, rol y funciones de los profesionales en administración de la educación, retos y desafíos al personal directivo en la actual Sociedad del Conocimiento y la Información.

- Competencias en el ejercicio de la administración para: planear, dirigir, coordinar, controlar y supervisar, habilidades intra e interpersonales, habilidades orales, escritas, de liderazgo y trabajo en equipo.

- Conocimientos y competencias de los profesionales en administración de la educación en el marco jurídico vigente.

Conocimientos en: Derecho como ciencia. Ramas del Derecho: Derecho Público, Derecho Administrativo, Derecho Constitucional, Derecho Educativo, Fuentes del Derecho escritas (convenios, leyes, decretos, reglamentos) y no escritas(costumbre, jurisprudencia), Importancia de la gestión jurídica en el ejercicio de la función de la administración de la educación, Jerarquía de las normas jurídicas para su utilización, Legislación Costarricense: Constitución Política de Costa Rica, Ley General de Administración Pública, Ley de Contratación Administrativa, Ley contra el Enriquecimiento llícito en el ejercicio de la Función Pública, Ley 7600, Legislación Educativa: Artículos referentes a la educación como derecho, su importancia, y administración, consagrados en las normas supremas del ordenamiento jurídico tales como Constitución Política de Costa Rica, los Convenios Internacionales y la Jurisprudencia de la Sala Constitucional. Asimismo, saberes generales sobre Leyes, Reglamentos, Decretos y demás documentos que aborden el sistema educativo, Procedimientos para llevar a cabo el debido proceso en cualquier acto administrativo que realice como funcionario público desde las garantías del debido proceso y el principio de legalidad.

Competencias interpersonales, intrapersonales, comunicativas, jurídicas, orales, escritas, de liderazgo, trabajo en equipo y negociación.

Instrumentalización: Entrevista dirigida a directores. Preguntas 1 y 2.

Nota: Elaboración propia, 2014. 
Tabla 2

Operacionalización objetivo específico 2: Normas jurídicas de uso común que utilizan los administradores de la educación costarricense en la práctica de la administración educativa moderna

OBJETIVO GENERAL: Análisis de los requerimientos jurídicos de la administración de la educación a la luz de las exigencias de la administración educativa moderna

Objetivo específico: Identificar las normas jurídicas de uso común que utilizan los administradores de la educación costarricense en la práctica de la administración educativa moderna

Categoría de análisis: Normas jurídicas de uso común que utilizan los administradores de la educación costarricense en la práctica de la administración educativa moderna

\section{Definición conceptual:}

Según Pacheco, citado por Arce (2012, p. 5): "la norma jurídica está constituida por: valores sociales que la colectividad ha decidido proteger y regular independientemente de su manera de presentarse".

De acuerdo con Benavides, Chavarría y González (1992) una aproximación al concepto de norma jurídica se define como un modelo de conducta humana exterior, bilateral, imperativa y coercitiva que regula la acción de los hombres con el objetivo de establecer un ordenamiento justo y organizado de la convivencia humana.

Cabanellas, citado por Arce (2012), señala que"el conjunto de normas que integran el Derecho Positivo, totalidad de principios, leyes y demás fuentes del Derecho e instituciones establecen las libertades y garantías generales del individuo en sus relaciones privadas y pública" (p. 34).

De acuerdo con Arce (2012), el ordenamiento jurídico es la estructura de las normas jurídicas que se encuentran vinculadas entre sí por una fundamentación común y unitaria (p. 33).

Garbanzo y Orozco (2007) indican que para enfrentar los diferentes desafíos que interpelan a la educación, se requiere de un nuevo paradigma de la administración de la educación, epistemológicamente renovada, de manera que el sistema educativo trabaje de acuerdo con parámetros de calidad, como condición para aspirar a lograr, con mayor pertinencia, los fines y objetivos de la educación. (p. 100)

Definición Operacional: Las normas jurídicas son aquellas herramientas legales, aprobadas y establecidas por la sociedad que emplean los administradores de la educación, las cuales les permiten respaldar, legitimar y fundamentar su actuar, de acuerdo con el ordenamiento jurídico costarricense y en aras de buscar una solución a las diferentes situaciones que enfrentan y en una sociedad que presenta constantes retos y desafíos. Estas situaciones que enfrentan los administradores podrían ser: demandas, cartas de apelación, rendimiento de cuentas ante otras instancias, recursos de amparo y procedimientos disciplinarios. El profesional en administración de la educación debe hacer uso de la siguiente normativa común:

- Constitución Política de Costa Rica

- Declaración Americana de los Derechos y Deberes del Hombre

- Pacto Internacional de Derechos Económicos, Sociales y Culturales

- Convención Americana sobre derechos humanos

- Protocolo Adicional a la Convención Americana sobre Derechos Humanos en Materia de Derechos Económicos, Sociales y Culturales

- Convención sobre los Derechos del Niño

- $\quad$ Estatuto del Servicio Civil: Título I y Título II

- Ley Fundamental de Educación

- Ley General de la Administración Pública

- Ley de Contratación Administrativa

- Ley contra el Enriquecimiento llícito en el ejercicio de la Función Pública

- Ley de Carrera Docente y su reglamento

- Ley 7600 y su reglamento

- Código de Educación

- Código de la Niñez y la Adolescencia

- Reglamento Interno de Trabajo del MEP 
- Reglamentos de Conserjería y Vigilancia

- Reglamento de Juntas y Patronatos

- Reglamento de Matrícula y Traslados

- Reglamento de Evaluación de los Aprendizajes

- Manual Descriptivo de Puestos Docentes del Servicio Civil

\section{Indicadores:}

-El director de la organización educativa identifica de una lista general las principales normas jurídicas de uso común para el ejercicio óptimo de su labor al enfrentar situaciones como demandas, cartas de apelación, rendimiento de cuentas ante otras instancias, recursos de amparo y procedimientos disciplinarios. Tales como: Constitución Política de Costa Rica, Declaración Americana de los Derechos y Deberes del Hombre, Pacto Internacional de Derechos Económicos, Sociales y Culturales, Convención Americana sobre derechos humanos, Protocolo Adicional a la Convención Americana sobre Derechos Humanos en Materia de Derechos Económicos, Sociales y Culturales, Convención sobre los Derechos del Niño, Estatuto del Servicio Civil: Título I y Titulo II, Ley Fundamental de Educación, Ley General de la Administración Pública, Ley de Contratación Administrativa, Ley contra el Enriquecimiento llícito en el ejercicio de la Función Pública, Ley de Carrera Docente y su reglamento, Ley 7600 y su reglamento, Código de Educación, Código de la Niñez y la Adolescencia, Reglamento Interno de Trabajo del MEP, Reglamentos de Conserjería y Vigilancia, Reglamento de Juntas y Patronatos, Reglamento de Matrícula y Traslados, Reglamento de Evaluación de los Aprendizajes, Manual Descriptivo de Puestos Docentes del Servicio Civil

-Existencia en la organización educativa de documentación y material normativo- legal general de fácil acceso, que le permita al director consultar cuando requiera abordar una situación jurídica en el ejercicio de su labor.

Instrumentalización: Entrevista dirigida a directores. Pregunta 3 y 4.

Nota: Elaboración propia, 2014.

\section{Tabla 3}

Operacionalización objetivo específico 3: Procedimientos de abordaje de situaciones jurídicas que realizan los administradores de la educación

OBJETIVO GENERAL: Análisis de los requerimientos jurídicos de la administración de la educación a la luz de las exigencias de la administración educativa moderna.

Objetivo específico: Reconocer los procedimientos de abordaje de las situaciones jurídicas que realizan los administradores de la educación del circuito 04 de la Dirección Regional de Educación San José Central.

Categoría de análisis: Procedimientos de abordaje de situaciones jurídicas que realizan los administradores de la educación.

\section{Definición conceptual:}

Un procedimiento consiste en seguir ciertos pasos predefinidos para desarrollar una labor de manera eficaz (Romero y Rodríguez, 2013) y tiene por objetivo obtener la mejor forma de llevar a cabo una actividad, considerando los factores de tiempo, esfuerzo y dinero (Gómez, citado por Romero y Rodríguez, 2013).

Según Chacón (2012),“la gestión jurídica en materia educativa, implica una serie de actividades de control por parte del administrador en educación" (p. 64).

Melgarejo (2007) indica que el administrador en sus relaciones con la Administración puede resultar titular de situaciones jurídicas que, en unos casos señala la ampliación de sus derechos y en otro, motivarán una limitación de los mismos. En el primer caso, se producen situaciones jurídicas de ventaja y dentro de ellas se suelen distinguir: las potestades, los derechos subjetivos y los intereses legítimos, que se enumeran por orden descendente en relación a la intensidad de las ventajas que suponen para el titular. En el segundo caso, es decir, en situaciones jurídicas de desventaja, se distinguen: el deber y la obligación.

Los artículos 214, 215 y 216 de la Ley General de Administración Pública (1978) establece las características generales del procedimiento administrativo: 


\section{Artículo 214.-}

1. El procedimiento administrativo servirá para asegurar el mejor cumplimiento posible de los fines de la Administración; con respeto para los derechos subjetivos e intereses legítimos del administrado, de acuerdo con el ordenamiento jurídico.

2. Su objeto más importante es la verificación de la verdad real de los hechos que sirven de motivo al acto final.

Artículo 215.-

1. El trámite que regula esta ley, se aplicará cuando el acto final haya de producir efectos en la esfera jurídica de otras personas.

2. El jerarca podrá regular discrecionalmente los procedimientos internos, pero deberá respetar esta ley.

Artículo 216.-

1. La Administración deberá adoptar sus resoluciones dentro del procedimiento con estricto apego al ordenamiento y, en el caso de las actuaciones discrecionales, a los límites de racionalidad y razonabilidad implícitos en aquél.

2. El órgano administrativo deberá actuar, además, sujeto a las órdenes, circulares e instrucciones del superior jerárquico, dentro de los límites de esta Ley.

De acuerdo con lo que se indica en el artículo 173, inciso 3) de la Ley General de Administración Pública (1978) se señala: "Antes de anular los actos referidos en este artículo, el acto final debe estar precedido por un procedimiento administrativo ordinario, en el que se hayan observado los principios y las garantías del debido proceso y se haya brindado audiencia a todas las partes involucradas".

En relación con el Debido Proceso, la Sala Constitucional ha emitido jurisprudencia importante, en el voto $5469-95$ se indica: "III.- Esta Sala ha señalado los elementos del derecho al debido proceso legal, (ver especialmente la opinión consultiva N¹73992), aplicables a cualquier procedimiento sancionatorio o que pueda tener por resultado la pérdida de derechos subjetivos. La Administración debe, en atención al derecho de defensa del administrado: Hacer traslado de cargos al afectado, lo cual implica comunicar en forma individualizada, concreta y oportuna, los hechos que se imputan; Permitirle el acceso irrestricto al expediente administrativo; Concederle un plazo razonable para la preparación de su defensa; Concederle la audiencia y permitirle aportar toda prueba que considere oportuna para respaldar su defensa. Fundamentar las resoluciones que pongan fin al procedimiento; Reconocer su derecho a recurrir contra la resolución sancionatoria".

El artículo 11, inciso 1) de la Ley General de la Administración Pública (1978) establece:“La Administración Pública actuará sometida al ordenamiento jurídico y solo podrá realizar aquellos actos o prestar aquellos servicios públicos que autorice dicho ordenamiento, según la escala jerárquica de sus fuentes".

Definición Operacional: Los procedimientos de abordaje de situaciones jurídicas son aquellas serie de acciones legales, concatenadas y eficaces que el administrador de la educación realiza desde su contexto y de acuerdo con los recursos humanos, materiales y temporales con los que cuenta para gestionar, supervisar, controlar y resolver situaciones legales sobre obligaciones, deberes, prohibiciones, sanciones o derechos de la comunidad educativa que dirige. Estas acciones deben enmarcarse en los principios del debido proceso y el principio de legalidad, establecidos en el ordenamiento jurídico costarricense.

\section{Indicadores:}

-Conocimiento del concepto de procedimiento administrativo, establecido por la legislación costarricense de acuerdo a lo que establece la Ley General de Administración Pública:

Artículo 214.-

1. El procedimiento administrativo servirá para asegurar el mejor cumplimiento posible de los fines de la Administración; con respeto para los derechos subjetivos e intereses legítimos del administrado, de acuerdo con el ordenamiento jurídico. 
2. Su objeto más importante es la verificación de la verdad real de los hechos que sirven de motivo al acto final.

-Cumplimiento de las etapas del debido proceso de acuerdo al ordenamiento jurídico costarricense. Hacer traslado de cargos al afectado, lo cual implica comunicar en forma individualizada, concreta y oportuna, los hechos que se imputan; Permitirle el acceso irrestricto al expediente administrativo; Concederle un plazo razonable para la preparación de su defensa; Concederle la audiencia y permitirle aportar toda prueba que considere oportuna para respaldar su defensa. Fundamentar las resoluciones que pongan fin al procedimiento; Reconocer su derecho a recurrir contra la resolución sancionatoria.

-Cumplimiento del Principio de Legalidad en el ejercicio de su función como administradores de la educación que indica el artículo 11 de la Constitución Política de Costa Rica y la Ley General de Administración Pública:“La Administración Pública actuará sometida al ordenamiento jurídico y solo podrá realizar aquellos actos o prestar aquellos servicios públicos que autorice dicho ordenamiento, según la escala jerárquica de sus fuentes".

Instrumentalización: Entrevista dirigida a directores. Pregunta 5.

Nota: Elaboración propia, 2014.

\section{Tabla 4}

\section{Operacionalización objetivo específico 4: Eventuales limitaciones jurídicas que enfrentan los administradores de la educación en el ejercicio de su gestión}

OBJETIVO GENERAL: Análisis de los requerimientos jurídicos de la administración de la educación a la luz de las exigencias de la administración educativa moderna.

Objetivo específico: Determinar las eventuales limitaciones jurídicas en el conocimiento jurídico que enfrentan los administradores de la educación y su impacto en la gestión.

Categoría de análisis: Las eventuales limitaciones jurídicas que enfrentan los administradores de la educación en el ejercicio de su gestión.

Definición conceptual: Nieto y Gordillo (2003, p. 53) señalan “las limitaciones del conocimiento jurídico, en todas sus dimensiones, se reflejan inevitablemente en las posibilidades de su transmisión, que también son reducidas". Según Garbanzo y Orozco (2007) para enfrentar los diferentes desafíos que a la educación, se requiere de un nuevo paradigma de la administración de la educación, epistemológicamente renovada, de manera que el sistema educativo trabaje de acuerdo con parámetros de calidad, como condición para aspirar a lograr, con mayor pertinencia, los fines y objetivos de la educación. (p. 100)

Definición operacional: las limitaciones en el conocimiento jurídico, son aquellos obstáculos que enfrentan los profesionales en administración de la educación de acuerdo a los desafíos que le plantea la actual sociedad del conocimiento.

Estos obstáculos están asociadas al conocimiento jurídico tales como: desconocimiento de convenios, códigos, leyes, reglamentos y decretos que atañen al sistema educativo(Constitución Política de Costa Rica, Declaración Americana de los Derechos y Deberes del Hombre, Pacto Internacional de Derechos Económicos, Sociales y Culturales, Convención Americana sobre derechos humanos, Protocolo Adicional a la Convención Americana sobre Derechos Humanos en Materia de Derechos Económicos, Sociales y Culturales, Convención sobre los Derechos del Niño, Estatuto del Servicio Civil:Título l y Titulo II, Ley Fundamental de Educación, Ley General de la Administración Pública, Ley de Contratación Administrativa, Ley contra el Enriquecimiento llícito en el ejercicio de la Función Pública, Ley de Carrera Docente y su reglamento, Ley 7600 y su reglamento, Código de Educación, Código de la Niñez y la Adolescencia, Reglamento Interno de Trabajo del MEP, Reglamentos de Conserjería y Vigilancia, Reglamento de Juntas y Patronatos, Reglamento de Matrícula y Traslados, Reglamento de Evaluación de los Aprendizajes, Manual Descriptivo de Puestos Docentes del Servicio Civil), falta de apoyo de asesores jurídicos, falta de capacitación en temáticas de legislación educativa y de recursos económicos y de tiempo para acceder a este tipo de formaciones. 
Indicadores: Eventuales limitaciones de conocimiento jurídico en el ejercicio de la función administrativa- educativa: -Desconocimiento de convenios, códigos, leyes, reglamentos y decretos que atañen al sistema educativo (Constitución Política de Costa Rica, Declaración Americana de los Derechos y Deberes del Hombre, Pacto Internacional de Derechos Económicos, Sociales y Culturales, Convención Americana sobre derechos humanos, Protocolo Adicional a la Convención Americana sobre Derechos Humanos en Materia de Derechos Económicos, Sociales y Culturales, Convención sobre los Derechos del Niño, Estatuto del Servicio Civil:Título I y Titulo II, Ley Fundamental de Educación, Ley General de la Administración Pública, Ley de Contratación Administrativa, Ley contra el Enriquecimiento llícito en el ejercicio de la Función Pública, Ley de Carrera Docente y su reglamento, Ley 7600 y su reglamento, Código de Educación, Código de la Niñez y la Adolescencia, Reglamento Interno de Trabajo del MEP, Reglamentos de Conserjería y Vigilancia, Reglamento de Juntas y Patronatos, Reglamento de Matrícula y Traslados, Reglamento de Evaluación de los Aprendizajes, Manual Descriptivo de Puestos Docentes del Servicio Civil)

- $\quad$ Falta de tiempo por la complejidad de funciones que debe llevar a cabo el personal directivo

- $\quad$ Falta de recursos económicos para acceder a formación profesional en estas temáticas

- $\quad$ Falta de asesorías para el profesional en administración de la educación de parte de sus patronos.

Instrumentalización: Entrevista dirigida a directores. Preguntas 6 y 7.

Nota: Elaboración propia, 2014.

La presente investigación se desarrolla bajo un enfoque cualitativo; por tal motivo, el instrumento utilizado fue la entrevista abierta como herramienta valiosa para la recolección de datos de manera personal.

Para la aplicación de los instrumentos se procede a realizar una visita a cada uno de los centros educativos, mediante una cita previa con cada director o directora. Asimismo, se realizaron dos visitas a la oficina de la supervisora del circuito 04 de la DRESJ para solicitar su autorización e información relevante para el presente estudio.

\section{Resultados}

\section{Conocimientos y competencias del administrador y de la administradora de la educación en el marco jurídico}

La gestión jurídica que realizan los directores y directoras desde sus centros educativos, les exige poseer una serie de competencias y conocimientos cognitivos que les permitan abordar, de manera profesional, los diferentes escenarios que implican la utilización de normas jurídicas y la capacidad para desenvolverse, frente a su personal, de manera óptima ante lo que se presenta.

Con respecto a los conocimientos en el marco jurídico que debe tener el administrador y la administradora de la educación, a criterio de la mayoría de los participantes consultados, el personal directivo debe poseer un amplio conocimiento de las leyes, los reglamentos, decretos, jurisprudencia y demás documentos emanados de los principales ministerios que guardan relación directa con su función como directores de centros educativos. 
Por otra parte, la mayoría de los participantes consultados resaltó la importancia que el administrador y la administradora de la educación gestione y administre correctamente el personal que tiene a cargo, teniendo muy claro en el nivel de teoría y práctica, los procedimientos correctos para la aplicación de sanciones, específicamente cómo realizar el debido proceso.

De acuerdo con lo indicado por los participantes consultados, señalan como los principales conocimientos en el marco jurídico que deben poseer los administradores y administradoras de la educación, los siguientes:

- Conocimiento de la Constitución Política de Costa Rica

- Prohibiciones, deberes y derechos del personal docente

- Principio de legalidad

- Leyes, reglamentos, decretos y circulares atinentes a la educación

- Jurisprudencia

- Debido Proceso

Lo anterior, evidencia que el personal directivo entrevistado posee una importante noción sobre los aspectos jurídicos que son necesarios para el desarrollo de una adecuada gestión; sin embargo, no resultan suficientes para un desempeño adecuado en las organizaciones educativas.

En cuanto a las competencias, el personal consultado señaló como elementos en común:

- Capacidad para comunicarse de manera asertiva con el personal, padres de familia y estudiantado

- Habilidad para negociar y ser conciliador en los diferentes procesos que se presentan con la comunidad educativa

- Capacidad de ejercer su liderazgo con la organización educativa que dirige

- Necesidad y habilidad de motivar constantemente a su personal.

Los profesionales en administración de la educación deben poseer los conocimientos y las competencias necesarias para enfrentar los retos que le demanda la administración educativa moderna; retos que, en la actualidad, traen de manera implícita elementos jurídicos y legales que les obliga a mantener un marco general y actualizado de conocimientos sobre temas fundamentales en el marco jurídico de su labor como: derecho educativo, derecho administrativo, derecho público, conocimientos sobre la Constitución Política, leyes, reglamentos, decretos, jurisprudencia y principios jurídicos que atañen de manera directa o indirecta su labor como administrador de la educación y su relación con la comunidad educativa. 


\section{Normas jurídicas de uso común en el campo de la administración educativa costarricense}

Para resolver las situaciones jurídicas que enfrentan los profesionales en administración de la educación dentro de su cotidianidad, deben consultar una serie de normas jurídicas que les permitan comprender, resolver y dar seguimiento a las diferentes situaciones de índole legal de la comunidad educativa con la que trabaja tales como: denuncias, demandas, procesos disciplinarios, recursos de amparo, rendición de cuentas, entre otras situaciones que requieren de manera ineludible de una adecuada gestión jurídica de su parte.

Ante la interrogante, al personal consultado, sobre las normas jurídicas de uso común que utilizan los profesionales en administración de la educación en el ejercicio de su labor, la mayoría señala como común denominador:

- Constitución Política de Costa Rica

- Ley de Carrera Docente

- Código de la Niñez y la Adolescencia

- Reglamento de Evaluación de los Aprendizajes

En la sociedad actual, los administradores y administradoras de organizaciones educativas deben manejar una amplia normativa jurídica que les permita orientar sus acciones de manera adecuada en la gestión jurídica que realizan desde sus puestos como líderes de la institución. No obstante, la población consultada evidencia un desconocimiento general de la normativa jurídica que resulta fundamental para gestar procesos administrativos y legales de manera adecuada.

\section{Procedimientos de abordaje a situaciones jurídicas realizado por los administradores y administradoras de la educación}

En la gestión jurídica que realiza cada profesional en su organización educativa, resulta fundamental que conozca y emplee de manera adecuada y de acuerdo con lo que establece el ordenamiento jurídico, los procedimientos de abordaje establecidos por la normativa, ante las diversas situaciones de índole legal que atañen a su función como administrador y administradora de la educación.

Un procedimiento inadecuado que violente de alguna manera los derechos de un miembro de la comunidad educativa o externo a esta, puede desencadenar múltiples problemas que requerirán un mayor uso del tiempo y de los recursos del personal directivo, restándole importancia a las otras áreas de gestión de la organización educativa para el cumplimiento de los objetivos costarricenses.

Lo anterior impacta de manera negativa la gestión del personal directivo, ya que al tener un desconocimiento total o parcial de la normativa y de los principios legales que sustenta 
estos procedimientos se cometerán errores de manera frecuente que generarán, de manera ineludible, más conflictos que le representen al líder organizacional y a su centro educativo la inversión de tiempo, esfuerzo y dinero desmedido, dejando de lado la gestión del currículo y otras áreas fundamentales para concentrarse únicamente en aspectos de índole legal.

\section{Eventuales limitaciones en el campo jurídico que enfrentan los administradores de la educación desde su gestión}

Los directivos de centros educativos, en aras de cumplir con las políticas educativas, los deberes y derechos de la población estudiantil y con las normas que los órganos ministeriales establecen con respecto a los deberes que todo funcionario debe cumplir, se ve implicado en procesos y situaciones de conflicto que, en la mayoría de las ocasiones, desembocan en temáticas legales, las cuales debe resolver de acuerdo con el bloque de legalidad vigente.

En la interrogante planteada al personal directivo sobre las limitaciones en el campo jurídico que enfrentan dentro de su gestión como administradores de la educación, llama la atención que la mayoría indicó:

- El poco o nulo apoyo que reciben de la Supervisión, Asesorías Jurídicas, Departamento de Asuntos Disciplinarios y abogados, en general, del Ministerio de Educación Pública.

- Los problemas que surgen de índole legal los resuelven"a ciegas" porque no tienen estudios en derecho.

- La ineficiencia del Ministerio de Educación para respaldar su labor como directores y de resolver situaciones con eficiencia y eficacia.

- Desconocimiento profundo de normativa legal, conceptos y principios jurídicos así como de etapas de procedimientos que se pueden aplicar en diferentes momentos.

- Falta de formación en las universidades.

- Falta de capacitación por parte del MEP en el ejercicio del puesto.

La información brindada por las personas profesionales en administración de la educación evidencia la falta de preparación y conocimiento en aspectos del ordenamiento jurídico, así como el poco respaldo del Ministerio de Educación para dar una respuesta oportuna a estos funcionarios y funcionarias, lo que impacta de manera perjudicial su desempeño como líderes organizacionales y el cumplimiento de las metas, los objetivos y los proyectos que cada centro educativo persigue. Con el propósito de subsanar las debilidades encontradas se elabora la siguiente propuesta de intervención. 


\section{Propuesta de intervención con los profesionales en administración de la educación}

De acuerdo con las debilidades encontradas en la presente investigación, se elabora una propuesta de intervención con los profesionales en administración de la educación del circuito 04 para que, por medio de una serie de módulos de capacitación, se les brinde las herramientas conceptuales, procedimentales y conductuales que respondan a las necesidades que externa el personal directivo en la gestión jurídica que realizan desde el ejercicio de su labor.

Es importante señalar que la propuesta se encuentra construida desde una metodología práctica y participativa que resulte significativa para el personal directivo y que a su vez, genere el aprendizaje de conocimientos y competencias gerenciales que les permita desenvolverse de forma óptima ante las situaciones de índole legal que enfrentan cotidianamente, ejerciendo una gestión jurídica de calidad que logre impactar, de manera positiva, su desempeño personal, laboral y profesional.

Para ello, se propone como objetivo general de esta propuesta:

- Elaborar un programa de capacitación dirigido al personal directivo del circuito 04 de la Dirección Regional de Educación San José Central, en saberes conceptuales, procedimentales y actitudinales para una adecuada gestión jurídica de la educación, a la luz de las exigencias de la administración de la educación moderna.

\section{Objetivos específicos de la propuesta}

- Determinar conceptos y principios jurídicos básicos en el marco de la administración educativa moderna.

- Identificar las principales características del derecho público y administrativo desde la óptica de la gestión jurídica de la educación.

- Reconocer la normativa jurídica de uso común desde la óptica de la gestión jurídica de la educación.

- Identificar las etapas del Procedimiento Administrativo desde la óptica de la gestión jurídica de la educación.

- Emplear correctamente los procedimientos que establece el ordenamiento jurídico costarricense al abordar situaciones jurídicas en sus centros educativos.

- Analizar la jurisprudencia emitida por la Sala Constitucional en relación con el sector educativo y su administración.

- Identificar las normas básicas de la resolución alterna de conflictos desde el ejercicio de la administración de la educación y desde la óptica de la gestión jurídica de la educación.

- Determinar las principales habilidades gerenciales y valores que debe poseer el personal directivo para una adecuada gestión jurídica de la educación. 
- Concientizar sobre la importancia de una adecuada gestión jurídica de la educación desde su función como administradores de la educación.

- Motivar al personal directivo en su gestión como líderes organizacionales.

Los módulos de aprendizaje se estructuran de la siguiente manera:

MÓDULO 1: Conceptos y principios jurídicos básicos en el marco de la administración educativa moderna

\section{a. El Derecho}

- Concepto de Derecho

- El Derecho y la Democracia

- Los Derechos Humanos

- Derechos Objetivos y Subjetivos

- Derechos Público vs. Derecho Privado

- Derecho Educativo

b. El Principio de Libertad o de autonomía de la voluntad

c. El Principio de Legalidad, la rendición de cuentas y la Responsabilización

- Estado de Derecho

- El Bloque de Legalidad

- El control de Legalidad

- La rendición de cuentas y la Responsabilización

\section{d. Principios del Procedimiento Administrativo}

- Debido Proceso (Principio de Defensa)

- Intimación e imputación

- Informalidad

- Motivación de los Actos

- Comunicación de los actos

- Celeridad 
- Oralidad

- Eficiencia

- Eficacia

- Razonabilidad y Proporcionalidad

- Acceso al expediente

MÓDULO 2: Introducción al derecho público y administrativo desde la óptica de la gestión jurídica de la educación

\section{a. Aspectos Generales del Derecho Administrativo}

- Estado de Derecho

- Ordenamiento Jurídico, normas escritas y no escritas

- El Bloque de Legalidad

- La Administración Pública

- El Funcionario Público y su investidura

\section{b. El Acto Administrativo}

- Concepto:

- Declaración de voluntad

- Unilateral

- Función Administrativa

- Productor de Efectos Jurídicos

- Elementos:

- Subjetivos

- Objetivos

- Formales

- Régimen de Nulidades:

- Nulidad Absoluta

- Nulidad Relativa

\section{c. El control interno}

- Concepto

- Objetivos

- Los órganos del control interno 
- Deberes de los jerarcas y titulares subordinados

- Los componentes del control interno: ambiente de control, valoración de riesgo, actividades de control

- Las normas de control interno (compilación básica)

- La auditoría interna: aspectos específicos sobre funciones, garantías y conflictos

- La autoevaluación del sistema de control interno y los planes de mejora

- El Sistema de Valoración de Riesgo Institucional (SERVI)

\section{d. La hacienda pública: su gestión y fiscalización}

- Conceptos: hacienda pública, fondos públicos

- Alcances

- El Sistema de control y fiscalización superior de la hacienda pública

- Modalidad de control según los distintos sujetos pasivos

- Potestades de la Contraloría General de la República

- Organización de la Contraloría General de la República y fiscalización del Ministerio de Educación Pública

\section{e. La Doctrina del Órgano}

- Concepto, naturaleza y función

- Los elementos del órgano

- El agente público

- Naturaleza de la relación entre agente y el Estado

- Relaciones entre órganos

- Las potestades de jerarquía

- Órdenes

- Vigilancia

- Control

- Instancia

- Delegación

- Disciplina

- Correctiva 


\section{MÓDULO 3: Normativa legal de uso común desde la óptica de la gestión jurídica de la educación}

\section{Jerarquía de las normas jurídicas según el ordenamiento jurídico costarricense}

\section{La Ley}

- Concepto de Ley: la fuerza de ley

- Titulares del Poder Legislativo

- Publicación de la Ley

- Contenido de la Ley

- Clases de Leyes: Leyes Fundamentales, Ordinarias, Decretos, Leyes o Medidas Excepcionales,

- Leyes de Ratificación de un Tratado Internacional, Leyes Delegadas

\section{El Reglamento}

- Concepto de reglamento

- Justificación de la Potestad Reglamentaria

- Distinción entre Reglamentos y Actos Administrativos

- Requisitos de Validez del Reglamento: competencias, jerarquía y procedimiento

- Límites Sustanciales: respeto a los principios generales del Derecho

- Las técnicas de control de la discrecionalidad

\section{Leyes principales que componen el Derecho Administrativo}

- Ley General de la Administración Pública

- Código Procesal Contencioso Administrativo

- Ley General de Control Interno

- Ley de Administración Financiera y Presupuestos Públicos

- Ley de Contratación Administrativa

- Estatuto del Servicio Civil: Título I y Título II

- Ley contra la Corrupción y el Enriquecimiento llícito en el ejercicio de la función pública

- Ley de la Jurisdicción Constitucional

- Ley de Protección al Ciudadano del Exceso de Requisitos y Trámites Administrativos 
MÓDULO 4: El Procedimiento Administrativo: las etapas fundamentales de todo proceso Aspectos Generales sobre el Procedimiento Administrativo

- Sobre el expediente

- Sujetos: el órgano director (competencia, nombramiento, integración)

- Tipos de Procedimiento Administrativo (Ordinario y Sumario)

\section{Etapas del Procedimiento}

- Medidas Cautelares

- Investigación Preliminar

- Decisión de Inicio y Acto de Inicio

- Audiencia Oral y prueba

- Acto Final

- Recursos de Apelación, Revocatoria

Procedimiento Administrativo Disciplinario aplicable al personal docente, administrativo-docente, técnico-docente y administrativo

- Análisis normativo

- Estatuto del Servicio Civil:Título I y Título II

- Código de Trabajo

Procedimiento Administrativo Disciplinario aplicable a los y las estudiantes del centro educativo

- Análisis normativo

- Reglamento de Evaluación de los Aprendizajes

- Ley Penal Juvenil

MÓDULO 5: Análisis de Jurisprudencia del sector educativo: interpretación jurídica de las normas.

- Jurisprudencia de la Sala Constitucional y estudio de casos 
MODULO 6: Resolución alterna de conflictos: el director como conciliador y mediador de situaciones de conflicto

- Mediación

- Conciliación

- Arbitraje

- Ley de Resolución Alterna de Conflictos

- Manual para la atención de conflictos en las instituciones públicas, MEP

\section{MÓDULO 7: El rol del personal directivo: competencias básicas en el ejercicio de la gestión jurídica de la educación}

- Técnicas de comunicación

- Uso de la palabra oral y escrita

- La comunicación asertiva: conceptos y técnicas para hablar y escribir mejor

- Estilos de liderazgo

De acuerdo con lo anterior, cada módulo de aprendizaje se estructura en subtemas que permiten una comprensión general para los profesionales en administración de la educación, acompañados de una metodología participativa y práctica que enriquecerá el conocimiento teórico y práctico que debe manejar todo administrador educativo desde el ejercicio de su puesto.

El programa de capacitación se encuentra aprobado por el Ministerio de Educación Pública y el Servicio Civil, este último otorgará un punto de carrera profesional al funcionario por la aprobación del curso.

El Ministerio de Educación Pública autorizará a los directores y directoras de cada centro educativo a asistir un día a la semana a recibir el programa de capacitación en gestión jurídica de la educación, para que logren adquirir las herramientas, conocimientos y competencias básicas para responder, de manera adecuada y de acuerdo con el ordenamiento jurídico costarricense, a las diferentes situaciones de índole jurídica que enfrentan desde su función como administradores de la educación.

\section{Responsables}

Los facilitadores de dicho programa son profesionales con conocimientos en derecho y administración de la educación que se desempeñan en puestos de relevancia en las oficinas centrales del Ministerio de Educación Pública, los cuales cuentan con amplia experiencia profesional y laboral en el marco de la gestión jurídica de la educación. 


\section{Duración}

El programa de capacitación tendrá una duración de 40 horas, distribuidas de la siguiente manera: 35 horas presenciales y cinco horas a distancia, las cuales el personal directivo utilizará para hacer tareas, análisis y ensayos cortos, propios del módulo de aprendizaje en el que se encuentran.

El personal directivo participante asistirá un día a la semana a dicha capacitación, en horario de 8:00 a.m. a 1:00 p.m.

La propuesta de capacitación se propone en los meses de marzo ya abril, al inicio de cada curso lectivo.

\section{Recursos humanos y materiales}

La capacitación para el personal directivo requiere de colaboración de personal del Ministerio de Educación Pública que cumpla el papel de facilitadores en cada módulo de aprendizaje, con conocimientos en derecho y en administración de la educación, así como poseer amplia experiencia laboral en ambos ámbitos.

Los funcionarios que pueden colaborar en este proceso son los asesores de la Dirección Regional San José Central y personal que labora en las oficinas centrales del Ministerio de Educación Pública.

Por otra parte, se requiere el préstamo de los centros educativos que cuenten con una sala amplia, proyector, computadora portátil y audio.

\section{Condiciones de viabilidad para la ejecución}

Para el cumplimiento del programa de capacitación se requiere:

- Voluntad política para que el Servicio Civil apruebe los módulos de aprendizaje y otorgue puntos en carrera profesional a los participantes que cumplan de manera óptima con cada módulo. De acuerdo con lo anterior se cumpliría con el procedimiento que solicita el Servicio Civil.

- Voluntad política por parte de los encargados del Ministerio de Educación Pública para asignar a los funcionarios los permisos respectivos para asistir a las diferentes sesiones de capacitación como participantes o facilitadores.

- Centro educativo sede

- Material didáctico

- Alimentación 


\section{Evaluación de la propuesta}

Una vez finalizados los siete módulos de aprendizaje, el programa de capacitación será evaluado con participación del personal directivo participante, el supervisor del circuito y el director regional de San José Central.

Dicha evaluación se realizará a partir de grupos focales con el personal directivo para conocer las debilidades y fortalezas del programa de capacitación, así como sugerencias y observaciones para su mejoramiento.

Con el supervisor y director regional se realizará una entrevista, con cada uno por separado, para conocer su perspectiva sobre el programa de capacitación, así como las fortalezas y debilidades que encontraron en el proceso.

\section{Conclusiones}

En general, a partir de la investigación se concluye que:

- Se evidencia la imperiosa necesidad de poseer conocimientos en el marco jurídico que atañe su función como líderes organizacionales.

- Es necesario que el personal directivo posea una serie de conocimientos básicos y generales en el marco jurídico.

- El personal directivo consultado señala la importancia de desarrollar competencias gerenciales.

- Las directoras y los directores consultados poseen un conocimiento parcial de las etapas del procedimiento administrativo.

- El personal directivo consultado señala enfrentarse, de manera constante, a una serie de limitaciones que obstaculizan su gestión de situaciones jurídicas.

- El personal directivo señala anuencia para capacitarse en temáticas jurídicas pero de manera práctica, funcional, real y estratégica.

- La gestión jurídica de la educación les está ocupando, a los profesionales en administración de la educación, más de la mitad de su tiempo laboral y personal.

- Los profesionales en administración evidencian desmotivación, angustia, inseguridad, impotencia y temor en sus relatos y frente a las situaciones jurídicas que deben enfrentar, de manera cotidiana, en sus centros educativos.

- La adecuada gestión jurídica en las organizaciones educativas se convierteen la herramienta que poseen los directores para enfrentar, de manera frecuente, situaciones legales al logro de los objetivos organizacionales y satisfacción de la comunidad educativa en general. 
- La sociedad actual en la que se encuentran inmersas las organizaciones educativas requiere un abordaje estratégico que responda a los retos, desafíos, necesidades, intereses y realidades que la sociedad de la información y el conocimiento demandan.

- La administración de la educación requiere un cambio de paradigma que le permita abrirse campo a un nuevo marco de conocimientos y competencias que respalden, formen y orienten, de manera eficiente y eficaz, la labor del personal directivo.

Una adecuada gestión jurídica por parte del profesional en administración de la educación va acompañada de acciones significativas de formación y capacitación para el personal directivo, por parte de las diferentes autoridades ministeriales y académicas.

Lo anterior, podrá garantizar al profesional en administración de la educación, en gran medida, un manejo integral y equitativo del centro y de la comunidad educativa, enfocado en las diferentes áreas de gestión directiva que lo aleje de trámites legales excesivos, costosos e innecesarios y lo acerque a una hábil resolución de situaciones jurídicas y al cumplimiento de los objetivos organizacionales y fines de la educación costarricense.

\section{Referencias}

Arce, C. (2012). Derecho educativo. San José, Costa Rica: EUNED.

Arroyo, J. (2011). Gestión estratégica de las organizaciones. San José, Costa Rica: EUCR.

Barrantes, R. (2007). Investigación: Un Camino al conocimiento. Un enfoque cualitativo y cuantitativo. San José, Costa Rica: EUNED.

Benavides, A., Chavarría, N. y González, E. (1992). Normas jurídicas para la administración de recursos (Financieros, Físicos y Humanos) en el Sistema Educativo Costarricense. (Seminario de Graduación de Licenciatura, Universidad de Costa Rica). Ciudad Universitaria Rodrigo Facio, San José, Costa Rica.

Chacón, A. (2012). Gestión del debido proceso en las acciones correctivas del CTP Abelardo Bonilla, circuito 05 Moravia, de la Dirección Regional San José Norte. (Tesis de Maestría, Universidad de Costa Rica). Ciudad Universitaria Rodrigo Facio, San José, Costa Rica.

Cons, N. (2004). La administración de la institución educativa. Recuperado en: www.observatorio. org/colaboradores/cons3

Cruz, C. y Pacheco, A. (2003). El conocimiento: la (re) construcción de un concepto. Revista Ciencia y Desarrollo, 29 (168), 4-9. Recuperado en: http://www.cyd.conacyt.gob.mx/ EdicionesAnteriores/img/Revista\%20CyD\%202003/CyD\%20168ene-feb2003.pdf 
Frade, L. (2009). Desarrollo de competencias en educación: desde preescolar hasta el bachillerato. México: Inteligencia Educativa.

Garbanzo, G. y Orozco, V. (2007). Desafíos del sistema educativo costarricense: un nuevo paradigma de la administración de la educación. Revista Educación, 31(002), 95-110. Recuperado en: http://revistas.ucr.ac.cr/index.php/educacion/article/viewFile/1246/1309

Garbanzo, G. y Orozco, V. (2010). Liderazgo para una gestión moderna de procesos educativos. Revista Educación, 34(001), 15-29. Recuperado en: http://www.redalyc.org/pdf/440/44013961001.pdf

García, N., Rojas, M. y Campos, N. (2000). La Administración Escolar para el cambio y el mejoramiento de las instituciones educativas. San José, Costa Rica: EUCR.

Hellriegel, D. y Slocum, J. (2002). Administración: un enfoque basado en competencias. México: Thompson. Hernández, R., Fernández, C. y Baptista, P. (2010). Metodología de la investigación. México: McGraw-Hill.

Ley General de Administración Pública. (1978). Recuperado en: http://www.ocu.ucr.ac.cr/Leyes/ Ley Administracion Publica.pdf

Melgarejo C., A. (2007). El administrado: concepto y clases capacidad y sus causas modificativas. Colaboración y participación de los ciudadanos en las funciones administrativas. Recuperado en: http://lavirtu.com/eniusimg/enius4/2007/12/adjuntos_fichero_137923.pdf

Ministerio de Educación Pública. (2014). Reglamento general de establecimientos oficiales de educación media. Recuperado en: http://www.mep.go.cr/sites/default/files/Reglamento_ General_Establecimientos_Oficiales_de_Educacion_Media.pdf

Nieto, A. y Gordillo, A. (2003). Las limitaciones del conocimiento jurídico. Madrid: Editorial Trotta.

Romero, A. y Rodríguez, R. (2013). Normas y procedimientos. Recuperado en: http://www. monografias.com/trabajos95/procedimientos/procedimientos.shtml\#ixzz30mkomlAA

Ruiz, A. (2006). Universalización de la educación secundaria y reforma educativa. San José, Costa Rica: EUCR.

Dirección General de Servicio Civil de Costa Rica. (2014). Manual Descriptivo de Puestos Docentes y Administrativo-Docentes. Recuperado en: http://www.apse.or.cr/webapse/10docum.htm 